\title{
Crescimento e Nutrição de Angico e Canafístula sob Calagem e Gessagem
}

\author{
Giovanno de Vargas ${ }^{1}$, Renato Marques ${ }^{1}$ \\ ${ }^{1}$ Universidade Federal do Paraná - UFPR, Curitiba/PR, Brasil
}

\begin{abstract}
RESUMO
O objetivo deste trabalho foi avaliar o efeito da aplicação de calcário e gesso sobre o crescimento e nutrição de leguminosas arbóreas. Os tratamentos consistiram em 5 doses de calcário, 1 de gesso e tratamento testemunha, com 5 repetições cada. Foram utilizadas as espécies angico (Anadanthera colubrina) e canafístula (Senna multijuga), sendo o experimento conduzido em casa de vegetação. Foram avaliadas pelo período de 7 meses as variáveis altura e diâmetro, biomassa, composição química das plantas e número e massa seca dos nódulos nas raízes. $\mathrm{O}$ calcário aumentou o $\mathrm{pH}$ e

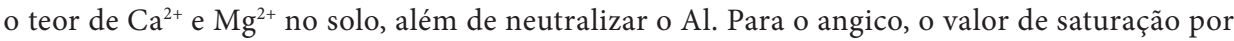
bases de 50\% promoveu maior crescimento e, para canafístula, foi de $20 \%$. Teores nutricionais nas folhas das duas espécies seguiram ordem de concentração $\mathrm{N}>\mathrm{Ca}>\mathrm{Mg}>\mathrm{K}>\mathrm{P}$. Não foram observadas correlações entre crescimento das plantas e teores foliares dos nutrientes.
\end{abstract}

Palavras-chave: Anadanthera colubrina, Senna multijuga, espécies nativas, fertilidade do solo.

\section{Growth and Nutrition of Angico and Canafístula under Liming and Gypsum}

\begin{abstract}
This study aimed to evaluate the effect of lime and gypsum application on the growth and nutrition of two leguminous trees. Treatments consisted of five rates of limestone, gypsum and a control treatment, with five replicates. Angico species (Anadanthera colubrina) and canafístula (Senna multijuga) were tested in a greenhouse experiment. Height and diameter were evaluated for a period of seven months. We evaluated the plants biomass, chemical composition, and number and dry weight of nodules on the roots. Lime increased $\mathrm{pH}, \mathrm{Ca}^{2+}$ and $\mathrm{Mg}^{2+}$ content in soils, besides the neutralization of the $\mathrm{Al}^{3+}$. For Angico, basis saturation promoted the highest growth for canafístula it was $20 \%$. Foliar nutritional content in the species, both, followed the order $\mathrm{N}>\mathrm{Ca}>\mathrm{Mg}>\mathrm{K}>\mathrm{P}$. There were no correlations between plant growth and leaf content of nutrients.
\end{abstract}

Keywords: Anadanthera colubrina, Senna multijuga, native forest species, soil fertility. 


\section{INTRODUÇÃO}

No Estado do Paraná, o tema preservação ambiental está quase sempre associado à Mata Atlântica (RBMA, 2011). Em parte, pelo fato de essa formação vegetal ser considerada um dos hotspot de biodiversidade (Myers ou Mittenmeier) mas também pela reduzida cobertura vegetal de Mata Atlântica atualmente existente (Ribeiro et al., 2009). A revegetação com espécies nativas é umas das estratégias importantes para aumentar a cobertura vegetal dessa formação vegetal e reverter essa situação.

Os solos de florestas da Mata Atlântica geralmente apresentam baixa disponibilidade de nutrientes, elevada acidez e altos teores de alumínio (Britez et al., 2006; Balbinot, 2009).

No processo de revegetação, a ocorrência de solos ácidos com baixos níveis de fertilidade pode ser um entrave. Algumas espécies da Mata Atlântica têm mostrado resposta diferenciada à calagem. Algumas espécies respondem positivamente em crescimento e outras não são influenciadas pela correção do solo (Furtini et al., 1999). A absorção de certos nutrientes, como o potássio $\left(\mathrm{K}^{+}\right)$, por exemplo, pode ser afetada pelas condições de acidez dos solos (Haridasan \& Araújo, 2005). Assim, a correção da acidez possui grande importância no desenvolvimento das plantas, uma vez que corrige os problemas causados pela acidez (Correa et al., 2008).

A calagem é uma das práticas menos trabalhosas e mais efetivas na correção da acidez do solo. Além disto, o Brasil possui vastas reservas de calcário (Fageira, 2001). Outra importante fonte de $\mathrm{Ca}^{2+}$ é o gesso $\left(\mathrm{CaSO}_{4} \cdot \mathrm{H}_{2} \mathrm{O}\right)$, pois além de fonte de cálcio, resulta em melhor crescimento radicular em camadas mais profundas e maior absorção de água e nutrientes pelas raízes das plantas, em decorrência do aumento da concentração de $\mathrm{Ca}^{2+}$ e da precipitação de $\mathrm{Al}^{3+}$ (Caires et al., 2003).

Outra limitação dos solos tropicais, em geral, é a baixa disponibilidade de nitrogênio (N). A utilização de plantas que formam nódulos e fixam simbioticamente o nitrogênio da atmosfera no processo de revegetação tem-se mostrado promissora (Peoples \& Craswell, 1992). Entretanto, Pelegrin et al. (2009) observaram que a acidez do solo, traduzida por $\mathrm{pH}$ baixo e concentrações elevadas de $\mathrm{Al}$, pode limitar todas as etapas do processo de infecção das raízes, formação de nódulos e assimilação do $\mathrm{N}$ em espécies leguminosas. Por outro lado, Silva \& Defelipo (1993) observaram que a calagem provoca aumento no número de nódulos, na fixação de $\mathrm{N}$ e aumento de matéria seca, altura e diâmetro do colo de leguminosas arbóreas.

Assim, diferentes espécies florestais podem ser afetadas ou não pelas condições ácidas de solo e de limitação nutricional. Para a maioria das espécies nativas da Mata Atlântica, sejam elas formadoras de nódulos ou não, são desconhecidas suas exigências nutricionais e os efeitos da acidez do solo sobre seu crescimento e nutrição. A rápida taxa de crescimento dessas florestas faz com que ocorra elevada demanda sobre os recursos do solo, em especial água e nutrientes (Melloni et al., 2008).

O desenvolvimento dessas espécies varia entre diferentes ambientes e as características dos solos e das plantas desempenham um importante papel na determinação de diferenças na adaptação dessas plantas. Informações em relação aos nutrientes encontrados no solo e as exigências nutricionais das plantas são importantes para a definição de estratégias para manutenção da sustentabilidade florestal (Santana et al., 2008).

Embora os nutrientes sejam fator fundamental no crescimento dessas espécies, principalmente devido à baixa fertilidade da maioria dos solos onde se desenvolvem, na maioria dos casos, poucas pesquisas têm sido realizadas sobre o assunto (Rosado et al., 2012).

Nesse contexto, mais pesquisas são necessárias com as diferentes espécies arbóreas, avaliando-se sua adaptação às diferentes condições de acidez do solo e/ou de disponibilidade de nutrientes, e seus efeitos sobre o crescimento, nutrição e nodulação dessas plantas. Dessa forma, este trabalho teve por objetivo avaliar o efeito do calcário e do gesso sobre atributos químicos do solo e sobre o crescimento, nodulação e nutrição de duas espécies de leguminosas arbóreas nativas da Mata Atlântica.

\section{MATERIAL E MÉTODOS}

\subsection{Coleta e análises de solo}

O solo utilizado para a condução do experimento foi coletado na Fazenda Experimental do Canguiri, da Universidade Federal do Paraná - UFPR, localizada na 
região metropolitana de Curitiba. A coleta de material foi realizada na camada $0-100 \mathrm{~cm}$ em solo classificado como Cambissolo Háplico Ta Distrófico típico (EMBRAPA, 2006). Desse solo foram determinados os principais atributos químicos (Tabela 1), conforme Marques \& Motta (2003).

\subsection{Delineamento experimental e condução do experimento}

O ensaio foi montado em delineamento experimental inteiramente ao acaso. Os tratamentos consistiram em 5 diferentes doses de calcário (calcário dolomítico), 1 dose de gesso $\left(\mathrm{CaSO}_{4} \cdot \mathrm{H}_{2} \mathrm{O}\right)$, além da testemunha $(\mathrm{T})$, com 5 repetições cada. As doses de calcário foram calculadas para elevar a saturação por bases (V\%) a $20 \%, 30 \%, 40 \%, 50 \%$ e $60 \%$. Assim, os tratamentos ficaram identificados como V20, V30, V40, V50, V60, G e T.

A quantidade de calcário aplicada foi obtida por meio da equação: NC $\left(\mathrm{t} \mathrm{ha}^{-1}\right)=(\mathrm{V} 2-\mathrm{V} 1)$.T.f $/ 100$, em que: $\mathrm{NC}=$ necessidade de calagem; $\mathrm{V} 1$ = valor da saturação por bases trocáveis do solo antes da correção; V2 = valor da saturação por bases trocáveis que se deseja; $\mathrm{T}$ = capacidade de troca de cátions; $\mathrm{f}=100 /$ PRNT; o calcário utilizado possuía PRNT de $72 \%$. O tratamento gesso teve sua dose calculada de maneira a fornecer uma quantidade de Ca equivalente à dose de calcário para elevar a saturação por bases a $40 \%$.

Foram utilizadas como plantas-teste as espécies leguminosas arbóreas angico [Anadenanthera colubrina (Vell.) Brenan] e canafístula [Senna multijuga (Rich.) Irwin], nativas da Mata Atlântica, da família botânica Fabaceae, em dois ensaios conduzidos simultaneamente, um com cada espécie de planta. Os ensaios começaram em 28 de fevereiro de 2012 e finalizaram em 28 de setembro de 2012. Foram utilizados vasos com 3 litros de volume, com $3 \mathrm{~kg}$ de solo cada.
Para evitar o efeito da umidade diferenciada sobre o crescimento das plantas, foi calculado o volume total de poros. Determinou-se a capacidade de campo através do volume de água retido no solo após sofrer saturação, até que fosse cessada a drenagem, a partir de um vaso de cada tratamento, umedecidos por um período em torno de 12 horas, até cessada a drenagem nos vasos, de maneira que a saturação pôde ser observada através de furos no fundo de cada vaso. Na sequência foi feita a pesagem dos vasos, para que fosse feita a irrigação diária conforme necessidade, de maneira que a condução das plantas foi feita com o objetivo de manter a umidade em torno de $70 \%$ da capacidade de campo do solo.

\subsection{Medições de crescimento, nodulação e análises químicas das plantas}

Foram realizadas medições de altura e diâmetro do colo com fita métrica e paquímetro digital, respectivamente, a cada 30 dias, pelo período de 7 meses, totalizando 8 medições. Após esse período foi efetuado corte e separação das plantas em caules e folhas e retirada das raízes, que tiveram seus nódulos destacados, contados e pesados em cada tratamento. Em seguida, o material foi colocado em estufa $\left(65^{\circ} \mathrm{C}\right)$ por aproximadamente 72 horas, para obtenção da matéria seca (MS).

Após a coleta de todos os dados de matéria seca, altura e diâmetro do colo, foi calculado o Índice de Qualidade de Dickson (Dickson et al., 1960), para se obter um índice de qualidade das mudas, medido através da equação: $\mathrm{IQD}=\mathrm{MST} /(\mathrm{H} / \mathrm{DC}+\mathrm{MSPA} / \mathrm{MSR})$, em que: MST = matéria seca total; $\mathrm{H}=$ altura; $\mathrm{DC}=$ diâmetro do colo; MSPA = matéria seca da parte aérea; $\mathrm{e}$ MSR = matéria seca da raiz.

As diferentes repetições de cada parte da planta foram agrupadas por tratamento. As folhas coletadas foram moídas para realização das análises químicas. A metodologia analítica usada foi a descrita por

Tabela 1. Atributos químicos do solo antes do início do experimento.

Table 1. Chemical properties of the soil before beginning the experiment.

\begin{tabular}{|c|c|c|c|c|c|c|c|c|c|c|c|c|}
\hline pH & pH & $\mathbf{A l}^{3+}$ & $\mathbf{H}^{+}+\mathbf{A l}^{3+}$ & $\mathrm{Ca}^{+2}$ & $\mathrm{Mg}^{+2}$ & $\mathbf{K}^{+}$ & SB & $\mathbf{T}$ & $\mathbf{P}$ & C & V & $\mathbf{m}$ \\
\hline $\mathrm{CaCl}_{2}$ & SMP & $\begin{array}{l}----\cdot \\
\end{array}$ & --------. & $-\cdots$ & $\mathrm{mol}_{\mathrm{c}} \mathrm{d}$ & 3 -.-. & 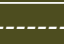 & ---- & $\mathrm{mg} \mathrm{dm}^{-3}$ & $\mathrm{~g} \mathrm{dm}^{-3}$ & $\%$ & $\%$ \\
\hline 3,50 & 3,80 & 5,90 & 25,60 & 1,20 & 0,20 & 0,07 & 1,47 & 27,07 & 1,40 & 14,30 & 5,00 & 80,00 \\
\hline
\end{tabular}


Martins \& Reissmann (2007). Os tecidos vegetais foram incinerados em mufla a $500{ }^{\circ} \mathrm{C}$ e posteriormente solubilizados em $\mathrm{HCl} 3 \mathrm{~mol} / \mathrm{L}$. O P foi determinado por colorimetria com vanadato-molibdato de amônio e leitura em espectrofotômetro Shimadzu, modelo UV/Vis 1240 Mini. As determinações de $\mathrm{K}^{+}$foram realizadas por fotometria de emissão. Os elementos $\mathrm{Ca}^{2+}, \mathrm{Mg}^{2+}$, $\mathrm{Fe}^{2+}, \mathrm{Mn}^{2+}, \mathrm{Cu}^{2+}, \mathrm{Zn}^{2+}$ e $\mathrm{Al}^{3+}$ foram determinados por espectrofotometria de absorção atômica. $\mathrm{O} N$ total e o C orgânico total foram determinados por combustão em analisador da marca ELEMENTAR, modelo Vario EL III.

\subsection{Análises estatísticas}

Os resultados obtidos foram submetidos à análise de variância através do F-teste e passaram pelo teste de Tukey (5\% de significância), para comparação das médias. Os valores de altura e diâmetro utilizados para realização das respectivas análises estatísticas são os da última medição realizada nas plantas, ao fim do sétimo mês do experimento. As análises foram feitas utilizando-se o Programa ASSISTAT versão 7.5.

\section{RESULTADOS E DISCUSSÃO}

\subsection{Influência dos tratamentos nos atributos químicos do solo}

Ao final do experimento, os resultados mostraram que a aplicação de calcário promoveu uma redução dos teores de alumínio trocável $\left(\mathrm{Al}^{3+}\right)$ e da acidez potencial $\left(\mathrm{H}^{+}+\mathrm{Al}^{3+}\right)$ e a elevação dos teores de $\mathrm{Ca}+$, $\mathrm{Mg}+$ e da saturação por bases (V\%), em comparação com a testemunha $(\mathrm{T})$. Nos tratamentos com calcário, os valores de V\% ficaram acima do esperado em função das doses aplicadas (Tabelas 2 e 3 ).

Assim, a prática da calagem promoveu benefícios no que diz respeito aos atributos químicos do solo. Apenas nas doses mais baixas (V20 e V30) ela não

Tabela 2. Atributos químicos do solo ao final do experimento com angico (Anadenanthera colubrina).

Table 2. Soil chemical properties at the end of the experiment with Angico (Anadenanthera colubrina).

\begin{tabular}{ccccccccccccc} 
Tratamentos & $\mathbf{p H}$ & $\mathbf{A l}^{\mathbf{3 +}}$ & $\mathbf{H}^{+}+\mathbf{A l}^{\mathbf{3 +}}$ & $\mathbf{\mathbf { C a } ^ { + 2 }}$ & $\mathbf{M g}^{+2}$ & $\mathbf{K}^{+}$ & $\mathbf{S B}$ & $\mathbf{T}$ & $\mathbf{P}$ & $\mathbf{C}$ & $\mathbf{V}$ & $\mathbf{m}$ \\
\hline Testemunha & 3,7 & 5,6 & 23,8 & 0,9 & 0,3 & 0,10 & 1,27 & 30,6 & 1,2 & 19,3 & 4,14 & 79,2 \\
V20 & 4,3 & 1,8 & 12,1 & 5,2 & 2,1 & 0,10 & 7,70 & 19,8 & 0,1 & 21,3 & 39,00 & 19,00 \\
V30 & 4,5 & 0,6 & 9,7 & 7,4 & 2,6 & 0,10 & 10,42 & 20,12 & 0,1 & 30,0 & 52,00 & 5,00 \\
V40 & 4,8 & 0,6 & 7,2 & 9,4 & 3,2 & 0,10 & 13,06 & 20,26 & 0,3 & 23,2 & 64,00 & 4,00 \\
V50 & 4,9 & 0,1 & 6,7 & 13,0 & 3,7 & 0,10 & 17,17 & 23,87 & 0,1 & 21,0 & 72,00 & 1,00 \\
V60 & 5,3 & 0,0 & 5,8 & 11,0 & 3,4 & 0,10 & 14,85 & 20,65 & 0,1 & 25,3 & 72,00 & 0,00 \\
Gesso & 4,0 & 3,9 & 17,6 & 8,0 & 1,0 & 0,05 & 9,41 & 27,01 & 0,3 & 28,4 & 35,00 & 29,00 \\
\hline
\end{tabular}

$\mathrm{SB}=$ soma de bases; $\mathrm{T}$ = capacidade de troca de cátions a $\mathrm{pH}$ 7,0; $\mathrm{P}$ = fósforo extraído por Mehlich; $\mathrm{C}$ = carbono orgânico total; $\mathrm{V}=$ saturação por bases; $\mathrm{m}$ = saturação de $\mathrm{Al}$.

Tabela 3. Atributos químicos do solo ao final do experimento com canafístula (Senna multijuga).

Table 3. Soil chemical properties at the end of the experiment with Canafístula (Senna multijuga).

\begin{tabular}{|c|c|c|c|c|c|c|c|c|c|c|c|c|}
\hline Tratamentos & pH & $\mathrm{Al}^{3+}$ & $\mathrm{H}^{+}+\mathrm{Al}^{3+}$ & $\mathrm{Ca}^{+2}$ & $\mathrm{Mg}^{+2}$ & $\mathbf{K}^{+}$ & SB & $\mathbf{T}$ & $\mathbf{P}$ & $\mathrm{C}$ & $\mathbf{V}$ & $\mathbf{m}$ \\
\hline ----- & $\mathrm{CaCl}_{2}$ & \multicolumn{7}{|c|}{ - } & $\mathrm{mg} \mathrm{dm}^{-3}$ & $\mathrm{~g} \mathrm{dm}^{-3}$ & $\%$ & $\%$ \\
\hline Testemunha & 3,6 & 5,7 & 24,6 & 1,0 & 0,50 & 0,07 & 1,57 & 26,17 & 1,40 & 21,30 & 6,00 & 78,40 \\
\hline V20 & 4,5 & 1,5 & 12,1 & 5,0 & 2,40 & 0,08 & 7,48 & 19,58 & 1,90 & 34,00 & 38,00 & 17,00 \\
\hline V30 & 5,0 & 0,3 & 8,4 & 6,7 & 2,70 & 0,08 & 9,48 & 17,88 & 1,20 & 25,30 & 53,00 & 3,00 \\
\hline V40 & 5,1 & 0,1 & 7,2 & 8,4 & 3,30 & 0,09 & 11,79 & 18,99 & 2,40 & 23,20 & 62,00 & 1,00 \\
\hline V50 & 5,4 & 0,0 & 7,2 & 9,6 & 3,50 & 0,09 & 13,19 & 20,39 & 1,60 & 38,60 & 65,00 & 0,00 \\
\hline V60 & 5,8 & 0,0 & 4,6 & 10,8 & 3,60 & 0,09 & 14,49 & 19,09 & 1,80 & 27,40 & 76,00 & 0,00 \\
\hline Gesso & 4,2 & 3,6 & 16,3 & 6,9 & 1,60 & 0,09 & 8,59 & 24,89 & 2,60 & 35,10 & 35,00 & 30,00 \\
\hline
\end{tabular}

$\mathrm{SB}=$ soma de bases; $\mathrm{T}$ = capacidade de troca de cátions a $\mathrm{pH} 7,0 ; \mathrm{P}=$ fósforo extraído por Mehlich; $\mathrm{C}=$ carbono orgânico total;

$\mathrm{V}=$ saturação por bases; $\mathrm{m}$ = saturação de $\mathrm{Al}$. 
mostrou eficiência total na neutralização do alumínio e no aumento do $\mathrm{pH}$, uma vez que a precipitação do $\mathrm{Al}^{3+}$ ocorre completamente quando o $\mathrm{pH}$ do solo atinge valores superiores a 5,4-5,5 (Almeida, 1986).

Os teores $\mathrm{de} \mathrm{Ca}^{2+}$ aumentaram, mas não linearmente com o aumento das doses de calcário, o que pode ser atribuído ao curto tempo de incubação do solo com os tratamentos.

O gesso, por ser mais solúvel e mais reativo, proporcionou elevação do cálcio bem superior à observada no tratamento $\mathrm{V} 30$, que recebeu a mesma quantidade de Ca mas na forma de calcário. No tratamento com gesso, o teor de $\mathrm{Mg}$ se mostrou bem inferior àquele de antes da aplicação do insumo, o que sugere lixiviação desse nutriente para o fundo dos vasos (Caires et al., 2003), uma vez que a incubação foi feita com regas frequentes.

Houve também diminuição expressiva da saturação por $\mathrm{Al}$ em todos tratamentos, com destaque para o tratamento V60, no qual, após 30 dias, a saturação já se encontrava nula. Mesmo o tratamento com gesso proporcionou diminuição na saturação por $\mathrm{Al}$, mas não pela diminuição dos teores de $\mathrm{Al}$ e sim pela elevação dos teores de Ca e, consequentemente, do valor de $\mathrm{T}$.

\subsection{Altura, diâmetro do colo e matéria seca das plantas}

Foi observado um pequeno incremento em altura e diâmetro ao longo do experimento. Esse comportamento podeser explicado, em parte, pela implementação do experimento durante o inverno, sendo assim resultado do período frio e das temperaturas mais baixas observadas durante os primeiros meses do experimento, além, também, dos baixos teores de $\mathrm{H}_{2} \mathrm{PO}_{4}$ - e $\mathrm{K}+$ observados no solo, que podem ter influenciado esses resultados (Tabelas 2 e 3).

O índice de qualidade de Dickson (IQD) foi usado para representar a qualidade das mudas em resposta aos tratamentos aplicados no solo (Tabelas 4 e 5). Quanto maior o índice de qualidade de Dickson, melhor a qualidade das mudas (Gomes, 2001). Os resultados mostraram que para as duas espécies a aplicação de calcário beneficiou a qualidade das mudas. No caso do angico, os maiores valores de IQD foram observados nos tratamentos V50 e V60, enquanto que no caso da canafístula o tratamento $\mathrm{V} 20$ foi o que resultou em maior IQD. Esses resultados são importantes na medida em que ressaltam a variabilidade das espécies florestais em

Tabela 4. Matéria seca das partes da planta e índice de qualidade de Dickson da espécie angico.

Table 4. Dry matter of the plants parts and Dickson quality index for Angico.

\begin{tabular}{|c|c|c|c|c|c|c|}
\hline \multirow{2}{*}{ Tratamentos } & Raiz & Caule & Folhas & Total & \multirow{2}{*}{ IQD } & \multirow{2}{*}{$\begin{array}{l}\text { Diferenças } \\
\text { estatísticas }\end{array}$} \\
\hline & (g) & (g) & (g) & (g) & & \\
\hline Testemunha & 5,90 & 4,01 & 2,40 & 12,31 & 1,36 & $\mathrm{~d}$ \\
\hline V20 & 6,37 & 6,35 & 2,52 & 15,24 & 2,24 & c \\
\hline V30 & 6,80 & 7,31 & 2,72 & 16,83 & 2,46 & b \\
\hline V40 & 7,22 & 5,82 & 3,05 & 16,09 & 2,20 & b \\
\hline V50 & 8,42 & 6,22 & 3,16 & 17,80 & 2,78 & a \\
\hline V60 & 6,92 & 6.98 & 4,45 & 18,35 & 2,46 & b \\
\hline Gesso & 5,71 & 4,21 & 2,35 & 12,27 & 1,77 & d \\
\hline
\end{tabular}

Tabela 5. Matéria seca das partes da planta e índice de qualidade de Dickson da espécie canafístula.

Table 5. Dry matter of the plants parts and Dickson quality index for Canafístula.

\begin{tabular}{|c|c|c|c|c|c|c|}
\hline \multirow{2}{*}{ Tratamentos } & Raiz & Caule & Folhas & Total & \multirow{2}{*}{ IQD } & \multirow{2}{*}{$\begin{array}{l}\text { Diferenças } \\
\text { estatísticas }\end{array}$} \\
\hline & (g) & (g) & (g) & (g) & & \\
\hline Testemunha & 0,58 & 1,22 & 1,15 & 2,95 & 0,37 & $\mathrm{e}$ \\
\hline V20 & 3,38 & 6,58 & 3,54 & 13,54 & 1,87 & a \\
\hline V30 & 2,50 & 3,37 & 2,64 & 8,51 & 1,34 & $b$ \\
\hline V40 & 2,12 & 2,90 & 3,00 & 8,02 & 1,22 & b \\
\hline V50 & 1,99 & 3,05 & 3,01 & 8,05 & 1,08 & $\mathrm{~b}$ \\
\hline V60 & 0,85 & 1,55 & 1,76 & 4,16 & 0,53 & d \\
\hline Gesso & 1,86 & 2,49 & 2,26 & 6,61 & 1,02 & c \\
\hline
\end{tabular}


termos de sensibilidade às condições de acidez do solo e a capacidade de resposta à aplicação de corretivos. Diferenças nesse sentido têm sido observadas entre diversas espécies florestais (Vale et al., 1996).

Segundo Marschner et al. (1996), espécies arbóreas de crescimento lento apresentam baixa resposta ao fornecimento de nutrientes, sendo adaptadas a solos pouco férteis. Dessa forma, espera-se que essas espécies tenham seu crescimento mais restringido quando se desenvolvem em solos ácidos, mostrando-se responsivas à correção da acidez. Ao passo que, com o avanço do desenvolvimento das plantas, espera-se que o estímulo ao crescimento proporcionado pela calagem seja menos pronunciado - por serem espécies em estágio inicial de crescimento a resposta aos tratamentos pode não ter sido tão eficiente como se esperava.

Conforme Barbosa et al. (1992), os resultados até certo ponto inesperados para certas espécies podem ser reflexo do comportamento próprio de cada uma, sem contudo estarem associados aos conceitos teóricos de grupos sucessionais, os quais não foram ainda confirmados para algumas espécies.

\subsection{Número e massa de nódulos}

As plantas da espécie canafístula não apresentaram nódulos em suas raízes. Isso, provavelmente, deveu-se ao pequeno desenvolvimento de suas raízes, como já foi evidenciado por Andrew (1976), em estudo com algumas espécies leguminosas.

Para o angico, o número de nódulos não respondeu de forma clara às doses de calcário. Os maiores valores foram observados para os tratamentos V20 e V50 e os menores valores, para os tratamentos T e V60, com valores intermediários para V30 e V40. O tratamento G também mostrou pouco efeito sobre o número de nódulos (Figura 1).

A matéria seca total dos nódulos seguiu tendência mais coerente, com maiores valores no tratamento V20 e decréscimo linear na massa de nódulos com o aumento das doses de calcário (Figura 2). Esses resultados sugerem a matéria seca de nódulos como parâmetro mais eficiente do que o número de nódulos para representar o efeito de tratamentos sobre a nodulação. Conforme Munns (1978), o cálcio tem importância no

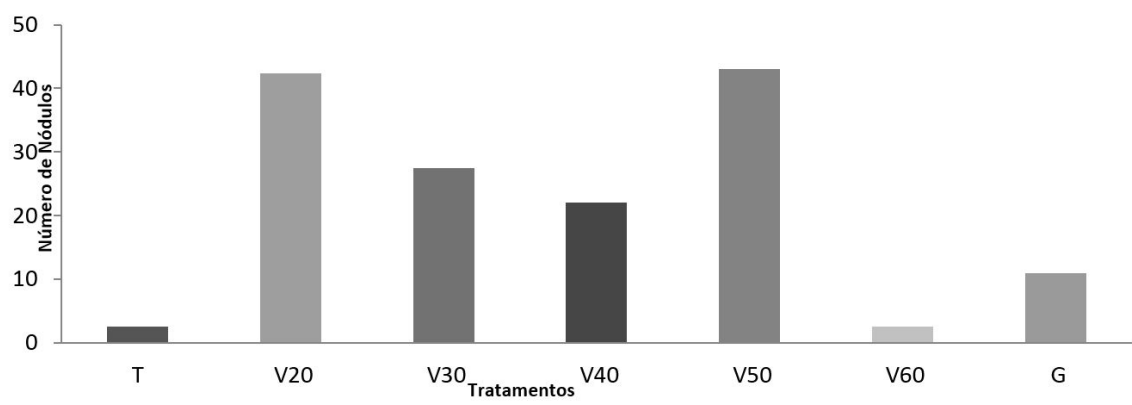

Figura 1. Número médio de nódulos por planta de angico em função dos tratamentos.

Figure 1. Average number of nodules per plant of Angico for the different treatments.

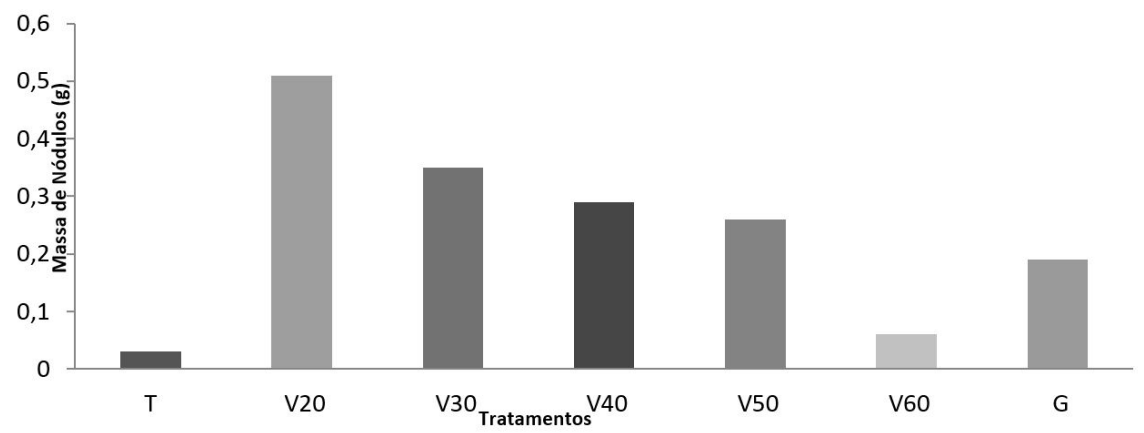

Figura 2. Massa seca média de nódulos por planta de angico em função dos tratamentos. Figure 2. Average dry matter of nodules per plant of Angico for the different treatments. 
processo de nodulação, a carência e o excesso desse elemento produzem efeitos adversos nas propriedades fisiológicas das plantas e na multiplicação das bactérias que formam os nódulos, que sofrem distúrbios na integridade estrutural da parede celular. A maior massa de nódulos no tratamento V20, no entanto, não refletiu em melhor IQD - os melhores valores de IQD foram observados nos tratamentos V50 e V60. Cabe salientar que o maior incremento das plantas se deu nos últimos dois meses do experimento, quando as temperaturas aumentaram.

\subsection{Teores nutricionais}

Os teores médios de macronutrientes encontrados nas folhas da espécie canafístula (Tabelas 6 e 7), para todos os tratamentos, seguiu a ordem $\mathrm{N}>\mathrm{Ca}>\mathrm{Mg}>\mathrm{K}>\mathrm{P}$. Já para o angico a sequência foi $\mathrm{Ca}>\mathrm{N}>\mathrm{Mg}>\mathrm{K}>\mathrm{P}$. Em relação aos micronutrientes, os teores seguiram a sequência $\mathrm{Fe}>\mathrm{Mn}>\mathrm{Zn}>\mathrm{Cu}$ para ambas as espécies e para a maioria dos tratamentos. É curioso observar o potássio com teores inferiores aos de $\mathrm{Mg}$, sendo esse um elemento que normalmente se posiciona entre os dois mais exigidos pelas plantas, juntamente com o nitrogênio (Marschner, 1995). Uma provável explicação para esse comportamento são os baixos teores de K no solo (Tabelas 2 e 3), o que teria limitado a sua incorporação nos tecidos foliares.

De maneira geral, os resultados dos nutrientes foliares mostram algumas diferenças entre as espécies estudadas. Maiores valores de $\mathrm{N}$ foram observados na espécie canafístula, entre 17,1 $\mathrm{g} \mathrm{e} 36,1 \mathrm{~g} \mathrm{~kg}^{-1}$, contra valores

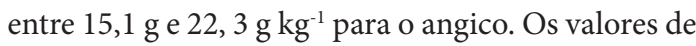
$P$ não diferiram nitidamente entre as espécies, ficando

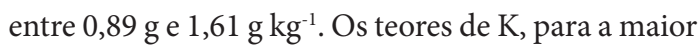
parte dos tratamentos, ficaram entre $3 \mathrm{~g}$ e $4 \mathrm{~g} \mathrm{~kg}^{-1}$, independentemente da espécie. Ca foi superior no angico, com valores entre $16,8 \mathrm{~g}$ e $27,9 \mathrm{~g} \mathrm{~kg}^{-1}$, contra valores entre $8,8 \mathrm{~g} \mathrm{e} 16,6 \mathrm{~g} \mathrm{~kg}^{-1}$ nas folhas de canafístula. $\mathrm{Mg}$ foi superior também nas plantas de angico, com valores entre 5,1 $\mathrm{g} \mathrm{e} 7,9 \mathrm{~g} \mathrm{~kg}^{-1}$, contra valores entre $2,7 \mathrm{~g} \mathrm{e}, 8 \mathrm{~g} \mathrm{~kg}^{-1}$ nas folhas de canafístula. Os teores de micronutrientes variaram bastante, chamando atenção apenas os valores de $\mathrm{Zn}$, maiores nas plantas de angico do que nas plantas de canafístula (Tabelas 6 e 7).

Os teores de $\mathrm{N}$ para a espécie angico não apresentaram nenhum padrão crescente ou decrescente em resposta às doses de calcário; mas o valor maior foi observado para o tratamento V50, um dos que também apresentou IQD maior. Os resultados foram

Tabela 6. Teores médios de macro e micronutrientes nas folhas de angico.

Table 6. Average contents of macro- and micronutrients in the leaves of Angico.

\begin{tabular}{|c|c|c|c|c|c|c|c|c|c|}
\hline \multirow{2}{*}{ Tratamentos } & $\mathbf{N}$ & $\mathbf{P}$ & $\mathbf{K}$ & $\mathrm{Ca}$ & $\mathrm{Mg}$ & $\mathrm{Fe}$ & Mn & $\mathrm{Cu}$ & $\mathrm{Zn}$ \\
\hline & & & $-\mathrm{g} \mathrm{kg}^{-1}$ & & & & $---m$ & & \\
\hline Testemunha & 15,1 & 1,49 & 4,43 & 23,73 & 7,93 & 178,5 & 44,64 & 20,83 & 37,69 \\
\hline V20 & 16,2 & 1,00 & 3,62 & 24,09 & 7,14 & 161,1 & 7,07 & 34,38 & 28,48 \\
\hline V30 & 15,3 & 1,04 & 3,22 & 20,02 & 4,67 & 439,3 & 114,40 & 14,54 & 29,09 \\
\hline V40 & 16,4 & 1,02 & 3,25 & 27,60 & 6,56 & 198,4 & 76,33 & 27,67 & 24,80 \\
\hline V50 & 22,3 & 1,21 & 4,03 & 27,90 & 6,05 & 193,5 & 60,05 & 15,25 & 41,94 \\
\hline V60 & 17,9 & 0,89 & 4,00 & 26,41 & 6,26 & 260,0 & 76,48 & 19,12 & 21,98 \\
\hline Gesso & 18,9 & 1,17 & 8,30 & 16,76 & 5,06 & 233,5 & 87,82 & 18,96 & 43,91 \\
\hline
\end{tabular}

Tabela 7. Teores médios de macro e micronutrientes nas folhas de canafístula.

Table 7. Average contents of macro- and micronutrients in the leaves of Canafístula.

\begin{tabular}{|c|c|c|c|c|c|c|c|c|c|}
\hline \multirow{2}{*}{ Tratamentos } & $\mathbf{N}$ & $\mathbf{P}$ & $\mathbf{K}$ & $\mathbf{C a}$ & $\mathrm{Mg}$ & $\mathrm{Fe}$ & Mn & $\mathrm{Cu}$ & $\mathrm{Zn}$ \\
\hline & ------ & --- & $\mathbf{g ~ k g}^{-1}$ & ----- & 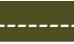 & \multicolumn{4}{|c|}{ 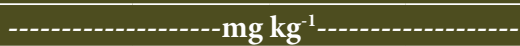 } \\
\hline Testemunha & 17,1 & 1,31 & 2,87 & 16,65 & 5,83 & 110,9 & 40,25 & 24,15 & 20,57 \\
\hline V20 & 30,2 & 1,21 & 4,17 & 8,81 & 4,39 & 73,78 & 116,50 & 10,67 & 23,30 \\
\hline V30 & 24,3 & 1,24 & 4,13 & 11,40 & 3,67 & 96,77 & 135,60 & 12,36 & 20,87 \\
\hline V40 & 36,1 & 1,04 & 3,29 & 7,61 & 2,66 & 83,25 & 100,80 & 10,77 & 18,60 \\
\hline V50 & 30,4 & 1,21 & 3,16 & 15,28 & 4,85 & 76,78 & 52,72 & 17,57 & 17,57 \\
\hline V60 & 24,6 & 1,61 & 3,79 & 14,14 & 5,04 & 104,9 & 56,50 & 13,45 & 19,73 \\
\hline Gesso & 18,2 & 1,17 & 5,05 & 8,53 & 2,83 & 62,62 & 149,7 & 15,65 & 24,46 \\
\hline
\end{tabular}


semelhantes aos encontrados por Zampier (2001) em mudas de erva-mate, em tratamentos com aplicação de Ca. Normalmente, existe maior disponibilidade de $\mathrm{N}$ em locais onde é feita a correção do solo (Hayatsu \& Kosuge, 1993). E isso parece ser o que aconteceu no caso do ensaio com canafístula, no qual os teores foliares de $\mathrm{N}$ foram bem superiores nos tratamentos com calagem.

Os teores de $\mathrm{P}$, para ambas as espécies, não apresentaram padrão de resposta aos tratamentos. A disponibilidade de $\mathrm{P}$ no solo e a absorção desse nutriente está ligada a fatores como mineralogia, textura, $\mathrm{pH}$, matéria orgânica e atividade microbiana do solo, entre outros (Bahia et al., 1983), além de a própria capacidade de absorver esse nutriente das plantas, o que pode provavelmente explicar esse comportamento.

Quanto ao K, são verificadas diferenças consideráveis nos valores no tratamento gesso; os teores desse elemento ficaram bem acima do nos demais tratamentos, sobretudo no ensaio com angico. Isso não era esperado, devido à grande quantidade de Ca adicionada nesse tratamento e aos baixos teores de $\mathrm{K}$ nesse solo (Tabelas 2 e 3), o que normalmente faria com que houvesse menor disponibilidade de K, uma vez que esses cátions competem pelo mesmo sítio de absorção nas plantas (Bull et al., 1993). Em parte isso poderia ser explicado por um efeito de concentração, uma vez que as plantas nesse tratamento cresceram pouco (Tabelas 4 e 5).

Em relação aos teores de $\mathrm{Ca}+\mathrm{e} \mathrm{Mg}+$, ambas espécies não apresentaram padrão de resposta definido. Não foi, como era esperado, observado um aumento do teor desses elementos com a elevação das doses de calcário. Respostas ao $\mathrm{Ca}+$ em culturas arbóreas não têm sido registradas com frequência, por sua ausência ou porque o efeito da ação corretiva do calcário supera possíveis efeitos ou deficiências de cálcio (Raij, 1991), explicando a importância do calcário não somente no suprimento da necessidade de Ca nas plantas, como também por sua ação corretiva no solo.

Segundo Caldeira et al. (2004), a prática da calagem, além de eliminar o efeito tóxico do alumínio, fornece cálcio, que é um elemento indispensável para o funcionamento das membranas celulares, garantindo absorção adequada dos nutrientes. Esses resultados demonstram que a aplicação de calcário favoreceu tanto o crescimento quanto a incorporação de macronutrientes, principalmente no angico.
A calagem não influenciou os teores dos micronutrientes na canafístula. Segundo Raij (1991), a calagem promove a diminuição da disponibilidade

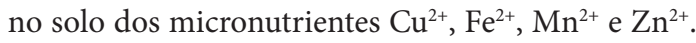
Guimarães (2000) elevou a saturação por bases de um solo arenoso de $11 \%$ para $34 \%, 49 \%, 64 \%, 79 \%$ e $94 \%$, e a de um solo argiloso de $15 \%$ para $37 \%, 51 \%, 65 \%, 79 \%$ e $93 \%$, verificando que houve diminuição nos teores de Fe, Mn e Zn conforme o aumento da saturação por bases. Esperava-se assim uma redução no teor com o aumento das doses de corretivo, pois quanto maior o valor do $\mathrm{pH}$, maior será a possibilidade de precipitação desses micronutrientes (Tedesco, 1999). Também não se constatou deficiência desses nutrientes nas folhas das duas espécies testadas.

\section{CONCLUSÕES}

A aplicação de calcário favoreceu o crescimento e a qualidade das mudas das duas espécies estudadas, como efeito da neutralização da acidez do solo e da elevação dos teores de $\mathrm{Ca}^{2+}$ e $\mathrm{Mg}^{2+}$ no solo.

O calcário mostrou-se mais efetivo que o gesso para o crescimento das plantas e a nodulação, indicando que a correção da acidez foi fator importante para a melhoria desses dois processos.

Os teores de nutrientes nas plantas variaram pouco em função dos tratamentos.

\section{STATUS DA SUBMISSÃO}

Recebido: 7 jun., 2016

Aceito: 19 jul., 2016

\section{AUTOR(ES) PARA CORRESPONDÊNCIA}

\section{Giovanno Radel de Vargas}

Universidade Federal do Paraná - UFPR, Rua dos Funcionários, 1540, CEP 80035-060, Curitiba, PR, Brasil e-mail: giovanno@ufpr.br

\section{REFÊRENCIAS}

Almeida JA. Comparação de métodos analíticos para avaliar a necessidade de calcário dos solos do estado de Santa Catarina. Revista Brasileira de Ciência do Solo 1986; 10(1): 143-150. 
Andrew CS. Effect of calcium, $\mathrm{pH}$ and nitrogen on the growth and chemical composition of some tropical and temperate pastures legumes. Nodulation and growth. Journal Agriculture 1976; 27(3): 611-616.

Bahia AFC Fo, Braga JM, Resende M, Ribeiro AC. Relação entre adsorção de fósforo e componentes mineralógicos da fração argila de Latossolos do Planalto Central. Revista Brasileira de Ciência do Solo 1983; 7(2): 221-226.

Balbinot R. Carbono, nitrogênio e razões isotópicas $\delta 13 \mathrm{C} e$ $\delta 15 N$ no solo e vegetação de estágios sucessionais de Floresta Ombrófila Densa Submontana [tese]. Curitiba: Setor de Ciências Agrárias, Universidade Federal do Paraná; 2009.

Barbosa LM, Asperti LM, Bedinelli C. Estudos sobre o estabelecimento e desenvolvimento de espécies com ampla ocorrência em mata ciliar. Revista do Instituto Florestal 1992; 4(1): 605-608.

Britez RM, Borgo M, Tiepolo G, Ferretti AR, Calmon M, Higa R. Estoque e incremento de carbono em florestas e povoamentos de espécies arbóreas com ênfase na Floresta Atlântica do sul do Brasil. 1. ed. Colombo: Embrapa; 2006.

Bull LT, Nakagawa J, Prado RC. Influência da relação K/ $(\mathrm{Ca}+\mathrm{Mg})$ do solo na produção de matéria seca e na absorção de potássio por gramínea e leguminosa forrageiras. II. Absorção de potássio em função da relação $\mathrm{K} /(\mathrm{Ca}+\mathrm{Mg})$ no complexo de troca do solo. Científica 1993; 21(1): 67-75.

Caires EF, Blum J, Barth G, Garbuio FJ, Kusman MT. Alterações químicas do solo e resposta da soja ao calcário e gesso aplicados na implantação do sistema plantio direto. Revista Brasileira de Ciência do Solo 2003; 27(1): 37-44.

Caldeira MVW, Rondon RM No, Schumacher MV. Eficiência do uso de micronutrientes e sódio em três procedências de acácia-negra (Acacia mearnsii De Wild.). Revista Árvore 2004; 28(1): 39-47. http://dx.doi.org/10.1590/ S0100-67622004000100006.

Correa JC, Bull LT, Crusciol CAC, Fernandes DM, Peres MGM. Aplicação superficial de diferentes fontes de corretivos no crescimento radicular e produtividade da aveia preta. Revista Brasileira de Ciência do Solo 2008; 32(4): 1583-1590. http://dx.doi.org/10.1590/S010006832008000400022 .

Dickson A, Leaf AL, Hosner JF. Quality appraisal of white spruce and white pine seedling stock in nurseries. Forestry Chronicle 1960; 36(1): 10-13. http://dx.doi.org/10.5558/ tfc36010-1.

Empresa Brasileira de Pesquisa Agropecuária - EMBRAPA. Sistema Brasileiro de Classificação de Solos. 2. ed. Rio de Janeiro: Embrapa; 2006.

Fageira NK. Efeito da calagem na produção de arroz, milho e soja em solo de cerrado. Pesquisa Agropecuária Brasileira 2001; 58(2): 825-831.

Furtini AE No, Resende AV, Vale FR, Silva IR. Liming effect on growth of native woods species from Brazilian Savannah.
Pesquisa Agropecuária Brasileira 1999; 34(5): 829-837. http://dx.doi.org/10.1590/S0100-204X1999000500014.

Gomes JM. Parâmetros morfológicos na avaliação da qualidade de mudas de Eucalyptus grandis, produzidas em diferentes tamanhos de tubete e de dosagens de N-P-K [tese]. Viçosa: Setor de Ciências Agrárias, Universidade Federal de Viçosa; 2001.

Guimarães GFPB. Avaliação de quatro forrageiras tropicais cultivadas em dois solos da Ilha do Marajó-PA submetidos a crescentes saturações por bases [dissertação]. Piracicaba: Setor de Ciências Agrárias, Escola Superior de Agricultura Luiz de Queiroz; 2000.

Haridasan M, Araújo GM. Perfil nutricional de espécies lenhosas de duas florestas semideciduas em Uberlândia, MG. Brazilian Journal of Botany 2005; 28(2): 295-303. http://dx.doi.org/10.1590/S0100-84042005000200010.

Hayatsu M, Kosuge N. Effects of urea fertilization and liming on nitrification in Cerrados soils (Brazil). Soil Science and Plant Nutrition 1993; 39(2): 367-371. http:// dx.doi.org/10.1080/00380768.1993.10417009.

Marques R, Motta ACV. Análise química do solo para fins de fertilidade. In: Lima RM, editor. Manual de diagnóstico da fertilidade e manejo dos solos agrícola. Curitiba: Universidade Federal do Paraná; 2003.

Marschner H, Kirkby EA, Cakmak I. Effect of mineral nutritional status on shoot-root partioniting of photoassimilates and cycling of mineral nutrients. Journal of Experimental 1996; 47(1): 1255-1263. PMid:21245257.

Marschner H. Mineral nutrition of higher plants. 2. ed. San Diego: Academic Press; 1995.

Martins APL, Reissmann CB. Material vegetal e as rotinas laboratoriais nos procedimentos químico-analíticos. Scientia Agraria 2007; 8(1): 1-17. http://dx.doi.org/10.5380/ rsa.v8i1.8336.

Melloni R, Melloni EGP, Alvarenga MIN, Vieira FBM. Avaliação da qualidade de solos sob diferentes coberturas florestais e de pastagem no sul de Minas Gerais. Revista Brasileira de Ciencia do Solo 2008; 32(6: 2461-2470. http:// dx.doi.org/10.1590/S0100-06832008000600023.

Munns DN. Soil acidity and nodulation. In: Andrew CS, Kamprath EJ, editor. Mineral nutrition of legumes in tropical and subtropical soils. Melbourne: Csiro; 1978.

Pelegrin R, Mercante FM, Otsubo IMN, Otsubo AA. Resposta da Cultura do Feijoeiro à Adubação Nitrogenada e à Inoculação com Rizóbio. Revista Brasileira de Ciencia do Solo 2009; 33(1): 219-226. http://dx.doi.org/10.1590/ S0100-06832009000100023.

Peoples MB, Craswell ET. Biological nitrogen fixation; investments, expectations and actual contributions to agriculture. Plant and Soil 1992; 141(1-2): 13-39. http:// dx.doi.org/10.1007/BF00011308.

Raij B. Fertilidade do solo e adubação. 1. ed. Piracicaba: Potafos; 1991. 
Reserva da Biosfera da Mata Atlântica - RBMA. Informações Gerais sobre a Mata Atlântica [online]. São Paulo; 2011 [citado em 2011 maio 10]. Disponível em: http://www. rbma.org.br/

Ribeiro MC, Metzger JP, Martensen AC, Ponzoni F, Hirota MM. Brazilian Atlantic forest: How much is left and how is the remaining forest distributed? Implications for conservation. Biological Conservation 2009; 142(6): 1141-1153. http://dx.doi.org/10.1016/j.biocon.2009.02.021.

Rosado AM, Rosado TB, Alves AA, Laviola BG, Bhering LL. Seleção simultânea de clones de eucalipto de acordo com produtividade, estabilidade e adaptabilidade. Pesquisa Agropecuária Brasileira 2012; 47(7): 964-971. http://dx.doi. org/10.1590/S0100-204X2012000700013.

Santana RC, Barros NF, Novais RF, Leite HG, Comerford NB. Alocação de nutrientes em plantios de eucalipto no Brasil. Revista Brasileira de Ciência do Solo 2008;
32(1): 2723-2733. http://dx.doi.org/10.1590/S010006832008000700016 .

Silva DJ, Defelipo VB. Necessidade de calagem e diferentes relações cálcio:magnésio para a produção de mudas de Eucalipto. Revista Árvore 1993; 17(1): 303-313.

Tedesco N. Produção de mudas de Acácia-negra (Acacia mearnsii De Wild.) adubadas com NPK [dissertação]. Santa Maria: Setor de Ciências Agrárias, Universidade Federal de Santa Maria; 1999.

Vale FR, Furtini AE No, Renó NB, Fernandes LA, Resende AV. Crescimento radicular de espécies florestais em solo ácido. Pesquisa Agropecuária Brasileira 1996; 31(1): 609-616.

Zampier AC. Avaliação dos níveis de nutrientes, cafeína e taninos após adubação mineral e orgânica, e sua relação com a produtividade na erva-mate (Ilex paraguariensis St Hil.) [dissertação]. Curitiba: Setor de Ciências Agrárias, Universidade Federal do Paraná; 2001. 